\title{
Phylogenetic patterns and conservation among North American members of the genus Agalinis (Orobanchaceae) James B Pettengill ${ }^{1}$ and Maile C Neel ${ }^{* 1,2}$
}

\author{
Address: ${ }^{1}$ Behavior, Ecology, Evolution, and Systematics Graduate Program, University of Maryland College Park, College Park, MD 20742 USA \\ and ${ }^{2}$ Department of Plant Science and Landscape Architecture and Department of Entomology, University of Maryland College Park, College Park, \\ MD 20742 USA \\ Email: James B Pettengill - jpetteng@umd.edu; Maile C Neel* - mneel@umd.edu \\ * Corresponding author
}

Published: 26 September 2008

BMC Evolutionary Biology 2008, 8:264 doi:10.1/86/147/-2/48-8-264

This article is available from: http://www.biomedcentral.com/I47|-2/48/8/264

(c) 2008 Pettengill and Neel; licensee BioMed Central Ltd.

This is an Open Access article distributed under the terms of the Creative Commons Attribution License (http://creativecommons.org/licenses/by/2.0), which permits unrestricted use, distribution, and reproduction in any medium, provided the original work is properly cited.
Received: 28 March 2008

Accepted: 26 September 2008

\begin{abstract}
Background: North American Agalinis Raf. species represent a taxonomically challenging group and there have been extensive historical revisions at the species, section, and subsection levels of classification. The genus contains many rare species, including the federally listed endangered species Agalinis acuta. In addition to evaluating the degree to which historical classifications at the section and subsection levels are supported by molecular data sampled from 79 individuals representing 29 Agalinis species, we assessed the monophyly of 27 species by sampling multiple individuals representing different populations of those species. Twenty-one of these species are of conservation concern in at least some part of their range.
\end{abstract}

Results: Phylogenetic relationships estimated using maximum likelihood analyses of seven chloroplast DNA loci (aligned length = I 076 base pairs (bp) and the nuclear ribosomal DNA ITS (internal transcribed spacer) locus (733 bp); indicated no support for the historically recognized sections except for Section Erectae. Our results suggest that North American members of the genus comprise six major lineages, however we were not able to resolve branching order among many of these lineages. Monophyly of 24 of the 29 sampled species was supported based on significant branch lengths of and high bootstrap support for subtending branches. However, there was no statistical support for the monophyly of $A$. acuta with respect to Agalinis tenella and Agalinis decemloba. Although most species were supported, deeper relationships among many species remain ambiguous.

Conclusion: The North American Agalinis species sampled form a well supported, monophyletic group within the family Orobanchaceae relative to the outgroups sampled. Most hypotheses regarding section- and subsection-level relationships based on morphology were not supported and taxonomic revisions are warranted. Lack of support for monophyly of Agalinis acuta leaves the important question regarding its taxonomic status unanswered. Lack of resolution is potentially due to incomplete lineage sorting of ancestral polymorphisms among recently diverged species; however the gene regions examined did distinguish among almost all other species in the genus. Due to the important policy implications of this finding we are further evaluating the evolutionary distinctiveness of $A$. acuta using morphological data and loci with higher mutation rates. 


\section{Background}

The increase in use of molecular systematics in studies of angiosperm evolution has resulted in numerous phylogenies describing relationships across a range of evolutionary history [1]. Studies of closely related species [2] are particularly important for filling in the tips on the angiosperm tree of life [3]. Phylogenetic hypotheses of the evolutionary relationships among members of the same genus provide frameworks for comparative research on mechanisms of diversification and speciation [4]. These phylogenies are also valuable resources for people concerned with conservation in that they provide a relatively objective means of quantifying evolutionary distinctiveness and resolving taxonomic ambiguities involving rare taxa [5-8]. It is this application to identifying lineages that are sufficiently distinct to warrant taxonomic status and thus are eligible for legal protection (i.e., species, subspecies, and varieties) that greatly interests us.

A basic assumption of many species concepts [e.g. [9-13]] and operational species delimitation methods [14] is that individuals of one species share common ancestry to the exclusion of members of other species. This shared common ancestry, which is a logical consequence of reproductive isolation between two groups, is expected to ultimately be reflected by genealogical exclusivity or monophyletic relationships inferred from phylogenetic analysis of DNA sequence or fragment data [11]. However, the rapidly accumulating phylogenies of congeneric taxa with mismatches between gene trees and an expected species tree $[15,16]$ is yielding a startling picture of the extent to which the expectation of monophyly is not met. Such mismatches can indicate imperfect taxonomy, lack of sufficient variation to detect differentiation, incomplete lineage sorting of shared ancestral polymorphisms, or contemporary hybridization or introgression. The amount of evolutionary time required for mutations to accumulate and for shared ancestral polymorphisms to sort out after speciation events [17-19] can make distinguishing among recently diverged taxa quite challenging. Coalescent theory predicts that it will take on the order of $\sim 8.7 \mathrm{~N}_{\mathrm{e}}$ generations for reciprocal monophyly of neutral, biparentally inherited loci to evolve in diverging lineages $[17,20]$. Thus, although the degree and duration of isolation necessary to achieve monophyly (especially across multiple loci) guarantees the evolutionary independence of monophyletic operational taxonomic units, absence of evidence for such independence, however, cannot automatically be assumed to mean that two entities are not reproductively isolated [21]. In these cases, additional evidence will be required to resolve ambiguities.

In this study, we examined phylogenetic relationships among 29 North American Agalinis (Raf.) species. This genus of flowering plants is restricted to the Western
Hemisphere where approximately 40 species occur in the eastern and central United States and Canada and approximately 30 species are found in South America, Mexico, and Central America [22-27]. Due to taxonomic uncertainties, the exact number of species in the genus is unclear; acceptance of particular taxa varies across authors and taxonomic revision is in progress. Historically, Agalinis was considered to be part of the family Scrophulariaceae but multiple phylogenetic analyses support placement in the family Orobanchaceae [28-30]. This plant family was traditionally associated with holoparasitism; however the broadened concept includes a number of autotrophic genera, such as Agalinis, that are hemiparasitic.

The majority of North American Agalinis species grow on the coastal plains of southern and southeastern North America. A secondary concentration of species occurs in the midwestern part of the continent and an even smaller number of species extend to the piedmont and to the coastal plains of the Mid-Atlantic, New England and the southern reaches of the Maritime Provinces in Canada [22-24,31,32]. Throughout this geographic range, habitats occupied by Agalinis species are typically grasslands and savannas, grassy openings in woodlands and forests, or other herb dominated habitats. Soil moisture requirements vary greatly across taxa, ranging from inundated wetlands (including bogs, streams, ponds, and salt marshes), to wetland edges, to dry uplands. Because Agalinis species thrive in relatively open sites with no or low cover of shrubs and trees, many of them are found in early successional habitats and are most abundant following fire or other disturbance events. Due to overall declining trends in grassland extent and condition resulting from both development and lack of natural disturbance, a number of Agalinis species are increasingly restricted to forest edges and anthropogenically maintained openings such as utility corridors, and road verges. Although the more ruderal species can be extremely abundant and widespread in these highly modified habitats, our observation indicated that some less abundant and more geographically restricted species are susceptible to mowing during the reproductive season, insufficient disturbance to remove woody vegetation, herbicide applications, and invasions of aggressively competitive non-native species.

General characteristics of the genus Agalinis include membranaceous, ephemeral corollas mostly with red-purple spots and yellow guide lines and wingless seeds that have variously reticulate seed coats $[22,23,33,34]$. Beyond the above characteristics, life form, morphology, anatomy, and floral form and color are variable, particularly in South American taxa. Unfortunately, relationships among the South American taxa are poorly understood, they are not included in any published classification schemes for 
the genus, and we were unable to obtain material to include them in this work. With exception of the perennial species A. linifolia, all North American species are annual herbs and all but three species (A. auriculata, A. densiflora, and A. heterophylla) have linear to filiform or scale-like leaves. Although mating systems have not been described for all members of the genus, the species that have been investigated include obligate outcrossing ( $A$. strictifolia [35]), mixed mating (A. acuta [36], A. skinneriana [37], A. obtusifolia [38], A. decemloba [38], and A. auriculata [39]), and predominantly selfing due to cleistogamy (A. neoscotica [40]).

The genus is taxonomically difficult and there have been numerous revisions of species and subspecies. In addition to taxonomic uncertainties, relationships among Agalinis species have been enigmatic and section-level classifications have been anything but stable. Pennell [23] originally suggested five sections within the genus but later suggested only three sections with five subsections [22]. Work based on seed, stem and leaf, and seedling characteristics as well as karyotypes [34,41-46] yielded revisions to Pennell's classification that recognized five sections (Erectae, Heterophyllae, Linifolieae, Purpureae, and Tenuifolieae) and three subsections within the Purpureae (Pedunculares, Purpureae, and Setaceae). Previous phylogenetic analysis of 15 Agalinis species based on 7323 aligned bp of nucleotide sequence variation at three cpDNA loci ( $r b c \mathrm{~L}, n d h \mathrm{~F}$, and $m a t \mathrm{~K})$ [47] did not fully support either Pennell's or Canne-Hilliker's section-level classifications, although one section and some subsections suggested by Canne-Hilliker appeared to represent natural groups. Specifically, monophyly of Section Erectae was supported but Sections Purpureae and Heterophyllae were polyphyletic. Subsection Pedunculares was monophyletic but did not appear to be related to other Section Purpureae taxa as had been presumed. Limited taxon sampling and relatively low cpDNA sequence variation in that study prevented more thorough evaluation of relationships among Sections Linifoliae and Tenuifolieae and other subsections within the Purpureae.

In the present study, we provide a more comprehensive phylogenetic treatment of the genus by examining 29 North American Agalinis species using 7 cpDNA loci and 1 nuclear locus. Our specific objectives included simultaneously evaluating the monophyly of sections, subsections, and species that have been named solely based on anatomy and morphology. Every polytypic section and subsection is represented by multiple species and 27 species are represented by multiple individuals. In contrast to traditional sampling approaches in systematics studies that include only one representative per species $[15,48]$, we were able to treat species labels as testable hypotheses [49]. The extensive sampling also provides a genus-wide context in which to evaluate the amounts and patterns of divergence among putative species that can be detected using the loci we sampled. This context is particularly critical for interpreting cases in which we fail to detect differentiation.

In addition to describing the evolutionary relationships among the sampled individuals, this study has important implications for conservation. We sampled 21 species that are considered imperiled (S2) or critically imperiled (S1) in at least 1 state in which they occur; 6 of these species are also globally vulnerable (G3 or G3-G4) and 3 are critically imperiled (G1) [Table 1; [50]]. Data on the divergence of and relationships among such a large number of species of conservation concern can help prioritize rare species for conservation $[51,52]$ by estimating their degree of uniqueness within the genus. We were specifically interested in addressing questions regarding the taxonomic status of three sets of species whose distinctiveness from one another and thus conservation status had previously been questioned: A. acuta and A. tenella, A. tenella and A. obtusifolia, A. decemloba and A. obtusifolia. The status of $A$. acuta has been questioned previously and Neel and Cummings [47] found only a single nucleotide difference between A. acuta and A. tenella across 4048 bp of cpDNA that included $r b c \mathrm{~L}$ and matK. Agalinis acuta occurs on the coastal plain in eastern Massachusetts; Rhode Island; on Long Island, New York; and in Maryland. Agalinis tenella occurs on the coastal plain from South Carolina south to Florida and west to Alabama [22]. Morphologically, A. acuta is distinguished from A. tenella by having a shorter corolla, smaller seeds, and shorter pedicels [22]. We were interested in the other two sets of species because the current taxonomic treatment in the USDA PLANTS database [27] suggests that $A$. tenella and A. decemloba are synonymous with A. obtusifolia [53]. If this taxonomic treatment is accurate and A. acuta is also not distinguishable, combining all four taxa would be appropriate and there would be important conservation policy consequences. As originally described, $A$. decemloba grows on the piedmont in Virginia, North Carolina, and South Carolina [22,23]. Agalinis obtusifolia is known from collections from Maryland south to Florida and then west through Georgia to Louisiana on both the piedmont and the coastal plain. Clarifying the taxonomic status of A. acuta [54] is essential because if it is not a species, subspecies, or variety it is not eligible for listing under the U.S. Endangered Species Act [55]. If it is synonymous with other species, the status of A. acuta would need to be revised based on the distribution, abundances, and threats of the populations representing those other species. 
Table I: North American Agalinis species including the number of individuals $(\mathbf{N})$ and conservation status of all species included in this study.

\begin{tabular}{|c|c|c|}
\hline Taxon' & $\mathbf{N}^{2}$ & Status $^{3}$ \\
\hline \multicolumn{3}{|l|}{ Section Erectae $(n=13)$} \\
\hline A. acuta & 9 & $\mathrm{GI} / \mathrm{SI}$ \\
\hline A. aphylla & 2 & G3-G4/S2 \\
\hline A. decemloba & 2 & NR \\
\hline A. gattingeri & 3 & G4/SI \\
\hline A. obtusifolia & 5 & G4-G5-Q/SI \\
\hline A. oligophylla & 3 & $\mathrm{G} 4 / \mathrm{SI}$ \\
\hline A. skinneriana & 3 & $\mathrm{G} 3 / \mathrm{SI}$ \\
\hline A. tenella & 6 & NR \\
\hline A. viridis & 2 & G4/SI \\
\hline A. keyensis & NS & \\
\hline \multicolumn{3}{|c|}{ Section Heterophyllae $(n=14)$} \\
\hline A. auriculata & 2 & G3-G4/SI \\
\hline A. calycina & 1 & GI/SI \\
\hline A. heterophylla & 3 & G4-G5/SI \\
\hline A. densiflora & NS & \\
\hline \multicolumn{3}{|l|}{ Section Linifoliae $(n=14)$} \\
\hline A. linifolia & 2 & G4?/SI \\
\hline \multicolumn{3}{|l|}{ Section Purpureae } \\
\hline \multicolumn{3}{|c|}{ Subsection Pedunculares $(n=13)$} \\
\hline A. edwardsiana & 1 & G4/S4 \\
\hline A. homalantha & 2 & $\mathrm{G} 5 / \mathrm{SI}$ \\
\hline A. pulchella & 2 & G4-G5/S3? \\
\hline A. strictifolia & 2 & G4/SNR \\
\hline A. navasotensis & 2 & $\mathrm{GI} / \mathrm{SI}$ \\
\hline A. peduncularis & NS & \\
\hline A. aspera & NS & \\
\hline \multicolumn{3}{|c|}{ Subsection Purpureae $(n=14)$} \\
\hline A. fasciculata & 3 & G5/SI \\
\hline A. harperi & 2 & G4?/SNR \\
\hline A. maritima & 2 & $\mathrm{G} 5 / \mathrm{S} 2$ \\
\hline A. paupercula & 2 & $\mathrm{G} 5 / \mathrm{SI}$ \\
\hline A. purpurea & 4 & $\mathrm{G} 5 / \mathrm{SI}$ \\
\hline A. tenuifolia & 3 & G5/SI \\
\hline A. pinetorum & NS & \\
\hline A. neoscotica & NS & \\
\hline A. virgata & NS & \\
\hline \multicolumn{3}{|c|}{ Subsection Setaceae $(n=14)$} \\
\hline A. laxa & 2 & G3-G4/S3? \\
\hline A. plukenettii & 2 & G3-G5/SI \\
\hline A. setacea & 2 & G5? \\
\hline A. stenophylla & NS & \\
\hline A. filifolia & NS & \\
\hline \multicolumn{3}{|l|}{ Section Tenuifolieae $(n=14)$} \\
\hline A. filicaulis & 2 & G3-G4/SI \\
\hline A. divaricata & 2 & G3?/SI \\
\hline A. nutallii & NS & \\
\hline \multicolumn{3}{|l|}{ Outgroup Species } \\
\hline Aureolaria pectinata & 1 & G5? \\
\hline Aureolaria pedicularia & 1 & G5 \\
\hline Brachystigma wrightii & 1 & G4 \\
\hline Dasistoma macrophylla & 1 & G4 \\
\hline
\end{tabular}

'Chromosome counts represent those known for the section or subsection based on extensive species sampling [43,45]. 2NS = Not Sampled.

${ }^{3}$ Conservation Status: global ranking (GI = critically imperiled; $\mathrm{G} 2$ = imperiled; $\mathrm{G} 3$ = vulnerable to extinction or extirpation; $\mathrm{G} 4=$ apparently secure; G5 = demonstrably secure or widespread)/highest state ranking for each species (SI-S5 are equivalent to the global scale but applied to within a single state) (USA); when a range or question mark (?) is given the precise conservation status is uncertain.; NR and SNR = not ranked. 


\section{Methods \\ Taxon sampling}

A total of 79 individuals representing 29 out of the $\sim 40$ putative North American Agalinis species were included in this study (Table 1). The sampled species represented all North American sections and subsections and all polytypic groups were represented by more than one species. The number of individuals per species ranged from 1-9 and when multiple individuals were used, they were from different populations. Sample locations for most species were selected somewhat opportunistically and often coincided with locations sampled for anatomical and morphological work by Dr. J. Canne-Hilliker. We attempted to include samples from geographically distinct locations for each species in order to capture the potential range of within-species variation (Additional file 1). Samples of $A$. acuta represent all geographic regions from which this species is known, and include most extant populations (Additional file 1). Samples of A. obtusifolia and A. tenella were also distributed to represent the range of each species (Additional file 1). The two A. decemloba populations were from the north central portion of the range. One representative of each of four outgroup species was also sampled: Aureolaria pedicularia (L) Raf., Aureolaria pectinata (L) Raf., Brachystigma wrightii (A. Gray) Pennell, and Dasistoma macrophylla (Nutt.) Raf. Fifteen of the Agalinis individuals and three of the four outgroup individuals were the same as those used in the previous phylogenetic study of the genus and related genera (Aureolaria pectinata is new and Seymeria pectinata Pursh was not included) [47]. Vouchers are located at University of Guelph, University of Maryland, Iowa State University, and University of Texas Austin. Specific information on the location of particular specimens is available on request. We did not collect voucher specimens from the endangered $A$. acuta because these populations are well documented by state Natural Heritage Programs and the U.S. Fish and Wildlife Service.

\section{DNA isolation, amplification, and sequencing}

Total genomic DNA was isolated from fresh or frozen ($80^{\circ} \mathrm{C}$ ) leaves and flower buds by grinding 50-100 mg of tissue to powder in liquid nitrogen with a mortar and pestle, and then using GenElute Plant Genomic DNA Kits (Sigma Chemical Company, St. Louis, Missouri, USA) or Qiagen DNEasy Kits (Qiagen Corporation, Valencia, California USA) following manufacturer's instructions.

We analyzed sequences from seven chloroplast gene regions $(m a t \mathrm{~K}, r b c \mathrm{~L}, n d h \mathrm{~F}, \operatorname{trn} \mathrm{T}$ (UGU)-trnF (GAA), rps2, $r p o \mathrm{~B}$, and $p s b \mathrm{~A}-t r n \mathrm{H})$ and the nuclear DNA (nDNA) locus ITS (18S-5.8S-26S). The first three cpDNA loci were used in the previously mentioned study [47] and they represent relatively slowly evolving portions of the chloroplast genome. Although there is rate variation among sites within these loci [47] that inform different levels of the phylogeny, they are most useful for resolving more ancestral relationships. The other chloroplast loci and the nuclear ITS locus were chosen because they have been shown to be informative at distinguishing among recently diverged taxa and even among populations within species [56-58]. Our strategy was to assay $r b c \mathrm{~L}$ and matK from at least one individual of each species to resolve the deeper relationships within the genus. We then attempted to sequence the other five loci from all sampled individuals. All but two of these loci were amplified using a single forward and reverse primer pair. The exceptions were trnTtrnF which required two PCR reactions per individual using $t r n \mathrm{~T}-\mathrm{a} / t r n \mathrm{~L}-\mathrm{d}$ and $t r n \mathrm{~L}-\mathrm{c} / \operatorname{trn} \mathrm{F}-\mathrm{f}$ [59]. The $r p s 2[28]$ locus was problematic for certain species but amplifications using the alternative forward primer $r p s 2-47 \mathrm{~F}$, instead of rps2-18F, were successful. Details of amplification and sequencing for $r b c \mathrm{~L}$ and $m a t \mathrm{~K}$ are given in Neel and Cummings [47]. In previous work $n d h \mathrm{~F}$ was extremely difficult to amplify from a number of Agalinis species and although we did not pursue additional $n d h \mathrm{~F}$ sequences, we used the ones available from Neel and Cummings [47] in our analysis.

Despite the well documented problems with using ITS for phylogenetic analyses, due to high copy number and difficulty optimizing PCR [e.g., [60]], we reliably obtained sequences using two primer pairs (ITS4 and ITS5 or ITS1 and ITS4)[61]. These primers did yield multiple PCR products and attempts to design species-specific primers for these taxa did not sufficiently reduce the number of copies. We therefore extracted the desired PCR product, (identified as the brightest band nearest to the target size), from an agarose gel using Qiagen's QIAquick Gel Extraction Kit according to the manufacturer's protocol. Inspection of the sequence trace curves confirmed that only a single copy had been sequenced.

All polymerase chain reactions (PCR) were done with Eppendorf MasterTaq PCR kits (Brinkman, Westbury, New York, USA) on MJ Research PTC-200 Thermal Cyclers. In general, the PCR temperature profile was 30 cycles of $94^{\circ} \mathrm{C}$ for $60 \mathrm{~s}$, annealing temperature set approximately $5^{\circ} \mathrm{C}$ below the lower of the two primer melting temperatures for $90 \mathrm{~s}, 72^{\circ} \mathrm{C}$ for $150 \mathrm{~s}$, and a final $15 \mathrm{~min}$ elongation period at $72^{\circ} \mathrm{C}$. Amplified DNA fragments were purified using the Qiagen QIAQuick PCR Purification Kit according to manufacturer's instructions, unless noted otherwise.

Because many of the individuals and species we investigated were closely related and thus sequence variation was likely to be low, four replicate sequencing reactions were carried out for both forward and reverse primers for a given locus, resulting in eight-fold coverage across most 
regions of all loci. This conservative sequencing strategy ensured accuracy and prevented erroneous base calls associated with sequencing error that can cause serious issues when only single sequences are analyzed. Sequencing reactions were conducted with BigDye Terminator v3.1 Cycle Sequencing chemistry (Applied Biosystems, Foster City, California, USA) with reactions set up in 96-well microtiter plates. Total reaction volume was $7 \mu \mathrm{l}(1-3 \mu \mathrm{l}$ DNA template, $1.5 \mu \mathrm{l} 5 \times$ Sequencing Buffer, $1 \mu \mathrm{l}$ primer [25 $\mu \mathrm{M}$ ], $0.5 \mu \mathrm{l}$ BigDye Terminator, and 1-3 $\mu \mathrm{l} \mathrm{ddH2O).}$ Cycle sequencing of purified PCR product was performed on an MJ Research PTC-200 Thermal Cycler and subsequent cleanup and preparation for sequencing was performed according to the manufacturer's protocol.

\section{Data analysis}

The program Sequencher v4.6 (Gene Codes Corporation, Ann Arbor, Michigan, USA) was used for base calling, quality assignments, and assembling consensus sequences for each sample from the replicate bi-directional sequence reads. Contigs for each locus exported from Sequencher were aligned using the default settings of MUSCLE [62]. BioEdit [63] was used to manually edit alignments of the cpDNA loci $r p s 2$, trnT-trnF, and psbA-trnH which had numerous insertions/deletions. Alignments were exported as FASTA files and then converted to non-interleaved NEXUS files using MacClade v4.06 [64]. Three different data matrices were created: 1) cpDNA only, 2) nuclear ITS sequences only, and 3) a concatenation of all sequences.

To evaluate the variability of each locus, we calculated the number of characters that were constant, parsimony informative, and autapomorphic using the default parsimony settings in PAUP* [65]. We also estimated the maximum likelihood pairwise distances between sampled individuals within and among Agalinis species for each locus separately. Nucleotide substitution model parameters for the maximum likelihood distance measures were chosen using MODELTEST [66]. MODELTEST evaluates the likelihood scores of the same neighbor-joining tree for each of the 56 nucleotide substitution models calculated using PAUP* and the best fitting model was chosen using Akaike's Information Criterion (AIC).

Phylogenetic analyses were performed using the program GARLI v0.951 (Genetic Algorithm for Rapid Likelihood Inference) [67]. GARLI performs heuristic phylogenetic searches under the GTR $+\Gamma+$ I (General Time Reversible with Gamma distributed rate heterogeneity and a proportion of invariant sites $[68,69]$ ) nucleotide substitution model where topologies are evaluated based on their likelihood. The program calculates the maximum likelihood of a topology in the same manner as PAUP* but uses a genetic algorithm [70] to more efficiently evaluate alter- native topologies. For each dataset, the best tree was found by running GARLI on the original data matrix with the default settings. We used likelihood ratio tests as implemented in PAUP* to assess whether branch lengths associated with the best topology inferred with GARLI were significantly greater than zero. To estimate the support for each node, phylogenies were created for 1000 bootstrap replicates of each dataset. A 50\% majority rule consensus tree of the 1000 bootstrap replicates from GARLI was then created using PAUP*. The support values at each node on the consensus tree were added to the best tree found by GARLI, which allowed us to display both node support values and branch lengths.

To decrease the computational time required to complete the bootstrap replicates we reduced the number of generations that were performed without finding a better scoring topology before a replicate was terminated from 10 000 to 5000. To complete the bootstrap analyses for the cpDNA and all loci combined datasets in a relatively short time we used Grid computing through The Lattice Project [71]. The GARLI executable was converted to a Grid service such that batches of bootstrap replicates were distributed among hundreds of computers where they were conducted asynchronously in parallel [72]. The 1000 bootstrap replicates for the smaller ITS dataset were accomplished on a single desktop computer.

We used the approximately unbiased (AU) test [73] as implemented in the program CONSEL [74] to evaluate whether a tree that constrained both A. acuta and A. tenella to be monophyletic was significantly worse than the best tree from an unconstrained analysis using the same data set. We repeated this test for each of the three data matrices. The AU test calculates a probability value of different topologies from bootstrap replicates of the site-likelihoods [73]. We also used the AU test to determine the influence of missing data on phylogenies inferred from the cPDNA and ITS datasets and to assess the degree of congruence between the phylogeny based on cpDNA loci and the phylogeny based on the complete data set. It is not possible to directly assess the incongruence between the topologies from the concatenated cpDNA dataset and the ITS locus because the data matrices differed in the number of individuals. However, given that the cpDNA dataset and the all-loci-combined dataset differed only in the inclusion of ITS, we used the AU test to compare these two topologies as a means to estimate the incongruence with the cpDNA phylogeny introduced by the ITS locus.

\section{Results and Discussion Characteristics of the sampled loci}

Despite extensive efforts, it was not possible to obtain sequences of all loci for all species (Table 2 \& Additional file 1). Total aligned length of the cpDNA dataset was 11 
Table 2: Summary of the cpDNA loci and the nDNA locus ITS used in this study

\begin{tabular}{|c|c|c|c|c|c|c|c|c|c|}
\hline \multirow[b]{2}{*}{ Locus } & \multirow[b]{2}{*}{$N$} & \multirow[b]{2}{*}{$\begin{array}{r}\text { Aligned Length } \\
\text { (bp) }\end{array}$} & \multirow[b]{2}{*}{$\begin{array}{r}\text { Characters Constant } \\
\text { (percent) }\end{array}$} & \multirow[b]{2}{*}{$\begin{array}{l}\text { Parsimony Informative } \\
\text { Characters (percent) }\end{array}$} & \multirow[b]{2}{*}{$\begin{array}{l}\text { Autapo- } \\
\text { morphies }\end{array}$} & \multirow[b]{2}{*}{$\begin{array}{c}\text { Nucleotide } \\
\text { Substitution Model' }\end{array}$} & \multicolumn{2}{|c|}{$\begin{array}{l}\text { Average Pairwise Difference } \\
(\text { (range })^{2}\end{array}$} & \multirow[b]{2}{*}{ Primer Source } \\
\hline & & & & & & & $\begin{array}{l}\text { Within } \\
\text { Species }\end{array}$ & $\begin{array}{l}\text { Among } \\
\text { Species }\end{array}$ & \\
\hline & & & $(88.40 \%)$ & $(3.68 \%)$ & & & $\mathrm{n} / \mathrm{a}$ & $\begin{array}{c}3.12 \% \\
(0-6.20 \%)\end{array}$ & $\begin{array}{c}\text { see } \\
\text { (Neel and Cummings 2004) }\end{array}$ \\
\hline$n d h F$ & 6 & $213 \mid$ & $\begin{array}{r}2002 \\
(93.95 \%)\end{array}$ & $\begin{array}{r}66 \\
(3.10 \%)\end{array}$ & 63 & TVM & $\mathrm{n} / \mathrm{a}$ & $\begin{array}{c}2.97 \% \\
(0.42-5.00 \%)\end{array}$ & $\begin{array}{c}\text { see } \\
\text { (Neel and Cummings 2004) }\end{array}$ \\
\hline$r b c L$ & 37 & $133 \mid$ & $\begin{array}{r}1205 \\
(90.53 \%)\end{array}$ & $\begin{array}{r}53 \\
(4.00 \%)\end{array}$ & 73 & GTR+I & $\begin{array}{c}0.17 \% \\
(0-0.39 \%)\end{array}$ & $\begin{array}{c}1.07 \% \\
(0-3.07 \%)\end{array}$ & $\begin{array}{c}\text { see } \\
\text { (Neel and Cummings 2004) }\end{array}$ \\
\hline rpoB & 78 & 375 & $\begin{array}{r}306 \\
(81.60 \%)\end{array}$ & $\begin{array}{r}52 \\
(13.87 \%)\end{array}$ & 17 & $\mathrm{GTR}+\Gamma$ & $\begin{array}{c}0.31 \% \\
(0-3.19 \%)\end{array}$ & $\begin{array}{c}2.15 \% \\
(0-5.40 \%)\end{array}$ & $\begin{array}{l}\text { http://www.kew.org/ } \\
\text { barcoding/update.html }\end{array}$ \\
\hline rps2 & 77 & 665 & $\begin{array}{r}520 \\
(78.20 \%)\end{array}$ & $\begin{array}{r}135 \\
(20.30 \%)\end{array}$ & 10 & $T V M+\Gamma+I$ & $\begin{array}{c}0.11 \% \\
(0-2.84 \%)\end{array}$ & $\begin{array}{c}4.37 \% \\
(0-8.59 \%)\end{array}$ & de Pamphilis et al. 1997 \\
\hline trnT-trnF & 79 & 1868 & $\begin{array}{r}1479 \\
(79.68 \%)\end{array}$ & $\begin{array}{r}320 \\
(17.13 \%)\end{array}$ & 69 & $\mathrm{TVM}+\Gamma+\mathrm{I}$ & $\begin{array}{c}0.29 \% \\
(0-3.29 \%)\end{array}$ & $\begin{array}{c}3.24 \% \\
(0-6.04 \%)\end{array}$ & Taberlet et al. 1991 \\
\hline psbA-trnH & 79 & 884 & $\begin{array}{r}669 \\
(75.68 \%)\end{array}$ & $\begin{array}{r}189 \\
(21.38 \%)\end{array}$ & 26 & $\mathrm{TVM}+\Gamma$ & $\begin{array}{c}0.20 \% \\
(0-2.94 \%)\end{array}$ & $\begin{array}{c}7.75 \% \\
(0-20.50 \%)\end{array}$ & $\begin{array}{l}\text { Sang et al. 1997; Tate and } \\
\text { Simpson } 2003\end{array}$ \\
\hline $\begin{array}{l}\text { All cpDNA } \\
\text { Loci }\end{array}$ & 79 & 11076 & $\begin{array}{r}9592 \\
(86.51 \%)\end{array}$ & $\begin{array}{r}950 \\
(8.57 \%)\end{array}$ & 545 & $T V M+\Gamma+1$ & $\begin{array}{c}0.31 \% \\
(0-2.0 \%)\end{array}$ & $\begin{array}{l}3.82 \% \\
(0-7.40 \%)\end{array}$ & \\
\hline ITS & 68 & 733 & $\begin{array}{r}504 \\
(68.76 \%)\end{array}$ & $\begin{array}{r}175 \\
(23.87 \%)\end{array}$ & 54 & $\mathrm{GTR}+\Gamma+\mathrm{I}$ & $\begin{array}{c}0.75 \% \\
(0-3.93 \%)\end{array}$ & $\begin{array}{l}6.51 \% \\
(0.14- \\
21.26 \%)\end{array}$ & White et al. 1990 \\
\hline All Loci & 79 & 11809 & $\begin{array}{r}10096 \\
(85.41 \%)\end{array}$ & $\begin{array}{r}1125 \\
(9.52 \%)\end{array}$ & 599 & $\mathrm{GTR}+\Gamma+\mathrm{I}$ & $\begin{array}{c}0.36 \% \\
(0.02-1.94 \%)\end{array}$ & $\begin{array}{c}4.05 \% \\
(0.04-7.99 \%)\end{array}$ & \\
\hline
\end{tabular}

$\mathrm{N}=$ the number of Agalinis species for each locus. Pairwise distances were calculated using Agalinis species only and do not include outgroup taxa.

I Nucleotide substitution model as selected using MODELTEST.

2 Pairwise differences are based on the maximum likelihood distances calculated using the nucleotide substitution parameters associated with the best fitting model identified using MODELTEST 
$076 \mathrm{bp}$ and the total aligned length for ITS was $733 \mathrm{bp}$ including only a few small (tri- or tetranucleotide) insertions. The aligned concatenated dataset of ITS and the 7 cpDNA loci was 11809 bp (Table 2).

The percent of constant characters among Agalinis species varied from $68.76 \%-93.95 \%$ for ITS and $n d h \mathrm{~F}$ respectively (Table 2 ). After $n d h \mathrm{~F}, r b c \mathrm{~L}$ had the largest percentage of constant characters $(90.53 \%)$. The number of parsimony informative sites for individual loci ranged from 52 (rpoB) to 320 (trnT-trnF) (Table 2). ITS exhibited the widest range of pair-wise maximum likelihood distances among species within the genus, ranging from $0.14 \%$ $21.26 \%$. The most conserved locus was $r b c \mathrm{~L}$ with pairwise distances among Agalinis species ranging from $0-3.07 \%$ and averaging $1.07 \%$; $p s b \mathrm{~A}-\operatorname{trn} \mathrm{H}$ had the largest range of among-species pairwise maximum likelihood distance of all the cpDNA loci, ranging from $0-20.50 \%$ and averaging $7.75 \%$ (Table 2).

Levels of variation we observed were similar to those found in other phylogenetic studies of congeneric species. The extensive length variation we observed in $\operatorname{trn} \mathrm{T}-\operatorname{trn} \mathrm{F}$ (shortest sequence length of 1228 bp compared to the length of the alignment of 1868 bp) has also been observed within the confamilial genus Pedicularis [75]. A study of Mimulus (Phrymaceae) [2] in which only the trnLtrnF portion of trnT-trnF was sampled found a similar degree of variability expressed as the percent of parsimony informative characters $(20.7 \%$ compared to $17.13 \%$ observed in this study). In Lymania (Bromeliaceae) 577 of 602 (96\%) bases of psbA-trnH were constant [76] compared to 669 of $884(75.68 \%)$ constant characters within this study. The maximum level of variation we observed at the nuclear ITS locus (ML distance $=21.26 \%$ ) is similar to that found in other genera within the Orobanchaceae (Pedicularis [77] and Orobanche [78]).

\section{General phylogenetic hypotheses}

The phylogenies inferred from the three data matrices differed in tree shape and support for specific relationships (Figs 1, 2, 3). Results of the AU test [73] suggested that topologies derived from the cpDNA and the complete data set (Figs. 1 \&3) were significantly different from one another $(P<0.05)$. To rule out the possibility that samples missing from the ITS dataset (Additional file 1) were causing some of the incongruence with the cpDNA phylogeny a reduced data matrix of the cpDNA loci was created that included only those samples also present in the ITS dataset. Results of the AU test $(P<0.05)$, indicated that the resulting topology (data not shown) was similar to the one from the complete cpDNA dataset, suggesting that missing individuals are not responsible for the incongruence between the nuclear and chloroplast DNA datasets.
Incongruences between phylogenies based on nDNA and cpDNA are not uncommon [e.g., [79-81]] and can indicate specific biological processes in species evolution. For example, hybridization has often been posited as an explanation for incongruence [82,83]. Alternatively, differences between the topologies might simply reflect the stochastic nature of the coalescent process [84]. The lack of bootstrap support for many of the internal nodes on the phylogenies (particularly those on the phylogeny inferred with the ITS dataset) prevent us from making strong statements regarding the meaning of the incongruences. Our discussion of relationships among putative taxa relies primarily on the full and chloroplast data sets because they tended to provide better support for inferred relationships. We point out specific instances where the estimates of relationships are different and well supported in the ITS data set.

All three topologies we examined provided strong statistical support for the monophyly of the sampled Agalinis species relative to the sampled outgroup species. Species now recognized as Agalinis have variously been included in the genera Gerardia, Tomanthera, and Virgularia. Gerardia had previously been applied to another taxon and the name was abandoned in favor of Agalinis [31]; Tomanthera and Virgularia are now synonymous with Agalinis. Aureolaria, Brachystigma, Dasistoma, Seymeria, and Esterhazya are considered close allies and at times have been considered congeneric with Agalinis [22,23]. Morphological evidence suggested Agalinis was a distinct genus from Brachystigma and Aureolaria [33], which our results clearly support. Phylogenetic analysis of the Orobanchaceae based on a single locus (phytochrome A) [85] indicates that the South American genus Esterhazya may be more closely related to Agalinis than are Aureolaria or Seymeria. South American species of Agalinis have not been included in any systematic studies and the only publicly available sequence from Esterhazya represents a locus we did not sample [87]. Sampling additional Esterhazya species and South American Agalinis species will be essential to fully understanding evolutionary relationships in this group as a whole and to confirm the monophyly of the genus.

\section{Section-level hypotheses}

Agalinis linifolia is the only perennial Agalinis species in North America and has additional distinguishing characters that have resulted in placement in its own monotypic section (Table 1) that has been suggested to be basal to the rest of the species. The unique ensemble of traits includes the type of thickenings on the inner walls of the seed coat cells [34], lack of yellow lines on the corolla, dense pubescence at the bases of the posterior corolla lobes, presence of aerenchyma in stems, conspicuous endodermis in roots, and palisade tissue in leaves that is developed more strongly towards the lower surface [23]. Monophyly of $A$. 


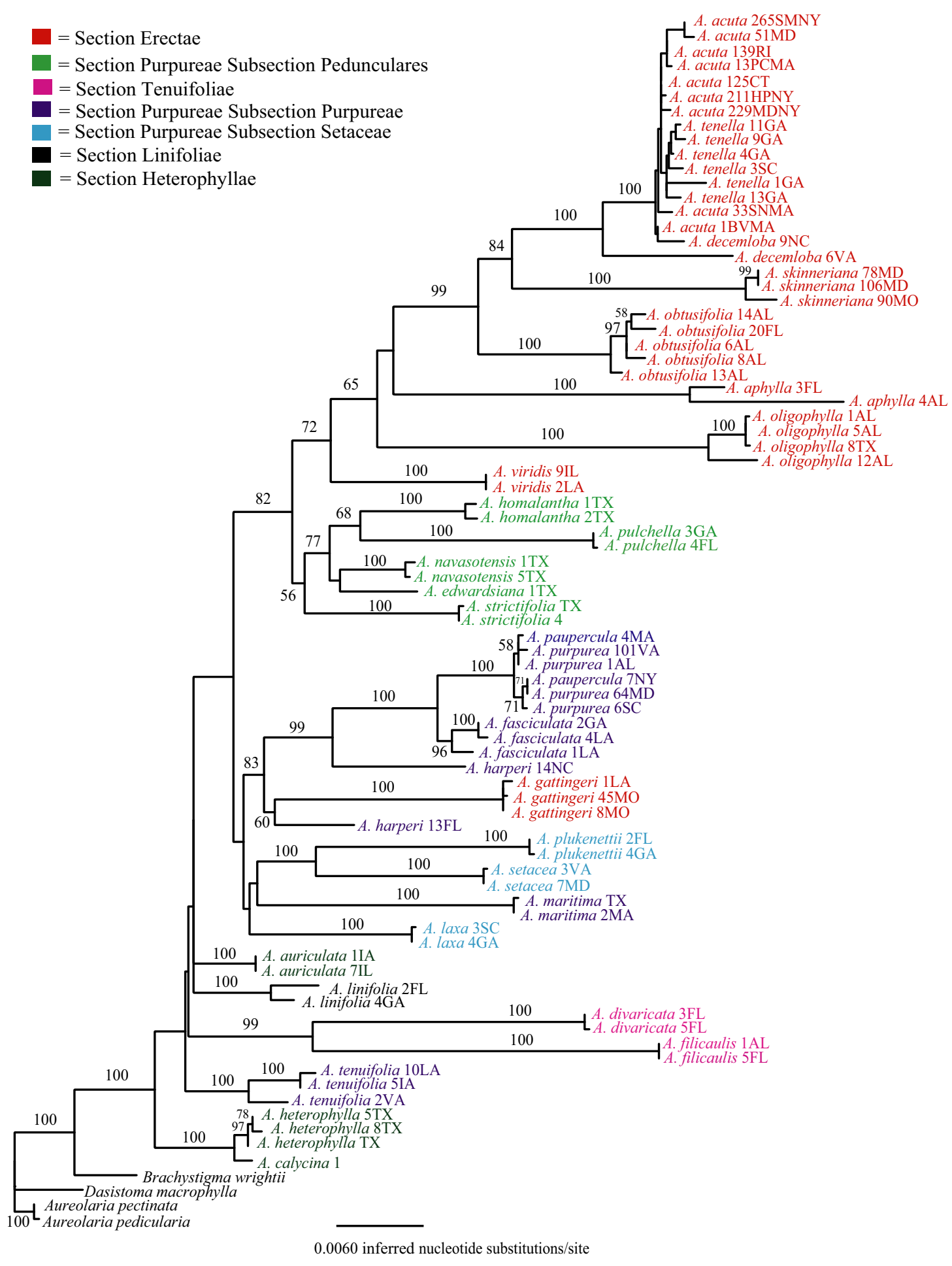

\section{Figure I}

Phylogenetic tree depicting evolutionary relationships among sampled taxa based on seven cpDNA loci. Branch lengths depict the inferred number of nucleotide substitutions per site. Numerals at nodes represent the percent of 1000 bootstrap replicates supporting that clade. The In likelihood of the tree is $-30816.27 \mathrm{I}$. 


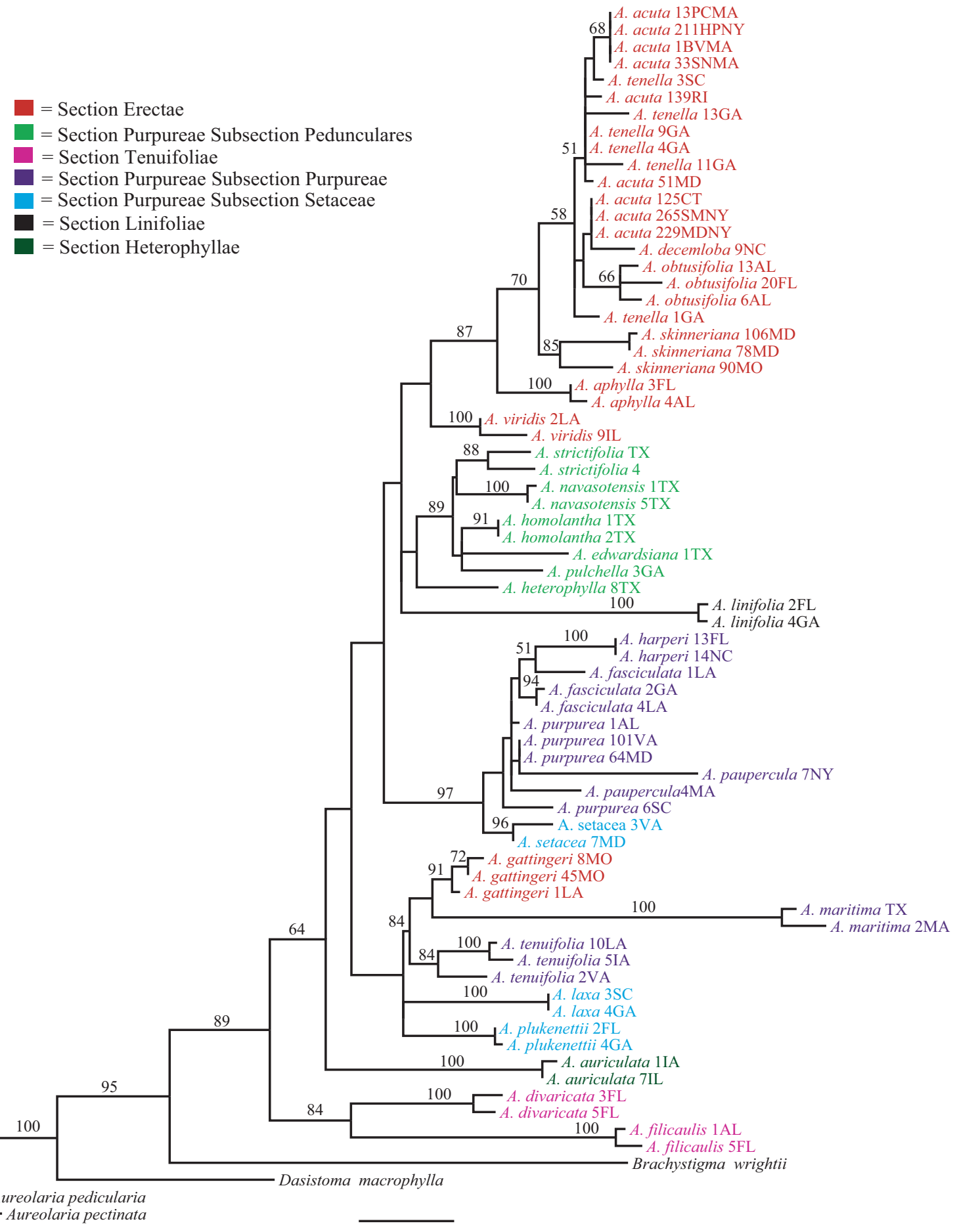

0.02 inferred nucleotide substitutions/site

\section{Figure 2}

Phylogenetic tree depicting evolutionary relationships among sampled taxa based on the nDNA ITS locus. Branch lengths depict the inferred number of nucleotide substitutions per site. Numerals at nodes represent the percent of 1000 bootstrap replicates supporting that clade. The In likelihood of the tree is -4250.1813 . 


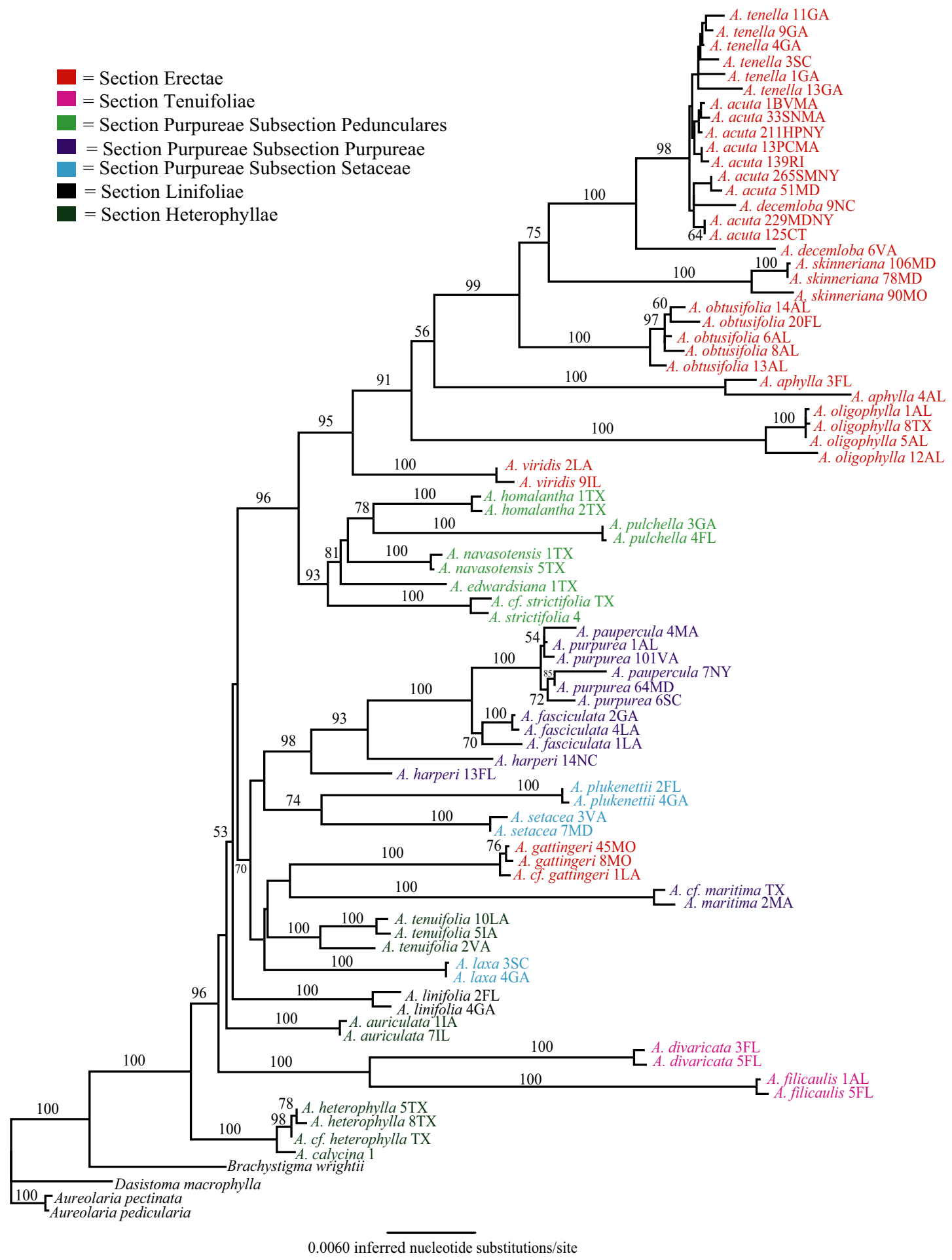

Figure 3

Phylogenetic tree depicting evolutionary relationships among sampled taxa based on a concatenated dataset of the seven cpDNA loci and the nDNA ITS locus. Branch lengths depict the inferred number of nucleotide substitutions per site. Numerals at nodes represent the percent of 1000 bootstrap replicates supporting that clade. The In likelihood of

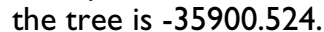


linifolia was supported; however, its placement within the genus remains ambiguous due to lack of support for surrounding nodes in all trees (Figs. 1, 2, 3). Despite this ambiguity, there is no evidence that this taxon is basal because it is placed within a relatively derived clade that is well supported. Further, a tree placing A. linifolia as basal had a significantly worse likelihood score than the best tree from the unconstrained analyses $(\mathrm{P}<0.05)$. Thus, the perennial growth habit appears to be derived within this genus of otherwise annual species.

Members of Section Heterophyllae have also been suggested to be basal within the genus based on having relatively large, broad, lanceolate leaves; leaf-like calyx lobes that are longer than the calyx tube; oblong or ovoidoblong capsules, and glabrous stems [22]. In particular, Pennell [22] suggested that A. auriculata most closely resembled the ancestral state of the genus based on also having relatively large corollas with pubescence limited to the area below the posterior sinus, and having posterior anther cells that are smaller than the anterior cells in addition to the characters described above [23]. Diagnostic aspects of leaf anatomy include thickened epidermal cell walls, bands of sclerids and fibers between the cortex and phloem, patterns of the subepidermal collenchyma on the leaf midribs, and lack of specialized trichomes [42,43]. We found only two of the three species hypothesized to comprise this section (A. heterophylla and A. calycina) to be monophyletic, and this well supported clade is indeed basal within the genus in the cpDNA and full data sets. Of these two species, we could obtain ITS sequence only for A. heterophylla, which was placed sister to the Subsection Pedunculares clade, but with low bootstrap support. The third species, A. auriculata, is not closely related to this group in any of the trees (Figs. 1, 2, 3). Agalinis auriculata was known to differ from $A$. heterophylla in leaf and stem pubescence [42], and the perceived importance of differences suggested by those features are supported by our molecular data (Figs. 1, 2, 3).

Section Tenuifolieae has long been taxonomically problematic [42]. Pennell [23] united Agalinis tenuifolia, A. divaricata and $A$. filicaulis in this section based on lack of pubescence on the posterior corolla and upper corolla lobes being arched forward rather than erect or reflexed back as is seen in the rest of the genus. Canne-Hilliker and Kampny [42] placed A. tenuifolia in Section Purpureae based on morphological and anatomical features, while retaining A. divaricata and A. filicaulis in Section Tenuifolieae. Most obviously, the upper corolla lobes in A. divaricata and A. filicaulis are less than $1 / 3$ the length of the lower lobes and the corolla is greatly flattened, occluding the opening to the throat. In contrast, the upper corolla lobes of A. tenuifolia are more equal in length to the lower lobes and the corolla throat is closer to round in cross sec- tion. Agalinis divaricata and A. filicaulis also share peculiar seedling and trichome types [41] and stem anatomy [42] that are not similar to any other Agalinis species and thus their placement has been challenging. High bootstrap support and the relatively long branch length supporting this clade in both the cpDNA and nDNA trees (Figs. 1, 2, 3 ) strongly support a sister relationship between A. divaricata and A. filicaulis. At the same time, branch lengths separating these two species are the longest of any sistertaxon pairs in the data set (Fig. 3). Relationships of this clade to other members of the genus depicted in the cpDNA tree conflict with those in the ITS tree. The cpDNA sequence data indicate that the most likely placement of the A. divaricata/A. filicaulis clade is sister to a clade including Section Purpureae (Fig. 1), and in the phylogenies from the ITS and the full data set these species have a more basal placement within the genus (Figs. 2 \&3).

Relationships of A. tenuifolia to other taxa are ambiguous; the cpDNA phylogeny supports a sister relationship of $A$. tenuifolia with all Agalinis species except the A. heterophylla/A. calycina clade (bootstrap support $=100 \%$ ) (Fig. 1). Phylogenies based on the ITS and full data sets indicate an alliance with A. maritima and A. gattingeri (bootstrap support $=84 \%$ ) (Figs. $2 \& 3$ ). In no case, however, does this species appear to be closely related to A. divaricata and A. filicaulis.

With the exception of A. gattingeri, which is found within the clade discussed above, the monophyly of Section Erectae is strongly supported in the full data tree (bootstrap support $=95 \%$ ) (Fig. 3). This section is united by the following genetic, anatomical, and morphological characters: chromosome number of $n=13$ [43], yellow-green colored foliage that does not blacken upon drying, small flowers that have relatively short corolla tubes and reflexed corolla lobes, pedicels longer than the calyx tube and light brown seeds $[34,42]$. Lack of blackening upon drying is thought to be due to low concentrations of aucubosides [38] that are at higher concentrations in other members of the genus. Placement of A. gattingeri apart from other members of the Erectae is problematic because it contradicts evidence that suggests close evolutionary relationships based on chromosome number [45] and the unique seed type [34] shared by other members of the section. However, A. gattingeri was always considered peripheral within Section Erectae due to its lack of anatomical features of the stem that are characteristic of the rest of the group [43]. Additional sampling is necessary to determine if this placement outside the Erectae is accurate or due to misidentification of the collections we sequenced or misinterpretation of the anatomical and morphological features. 
Section Purpureae as defined by both Canne-Hilliker and Pennell was the largest section in the genus and it has been considered to have 3-5 subsections. Members were united by having globose capsules, dark brown seeds, narrow leaves that turn black upon drying and calyx lobes that are shorter than the calyx tube. We found little support for any of the historical concepts of this section or the majority of the recognized subsections (Figs. 1, 2, 3). Only Subsection Pedunculares appears to be a natural group (Figs. 1 \&3); however, this subsection is sister to taxa comprising Section Erectae rather than to other taxa considered to be in the Purpureae. Subsection Pedunculares was considered to be distinct from the Erectae based on corolla form and pubescence patterns, seed color and surface patterns, and stem and leaf anatomy [43]. Neel and Cummings [47] had previously suggested a sister relationship between the Pedunculares and the Erectae but their results were based on fewer species and the relationship did not have strong bootstrap support. Aligning the Pedunculares with the Erectae unites all the taxa with 13 chromosomes except A. gattingeri, which is placed with species considered to be in Section Purpureae. If not for the problematic placement of A. gattingeri, it would appear that $n=14$ was ancestral and the haploid chromosome number of 13 arose only once in the genus.

We found no support for the monophyly of Subsections Purpureae or Setaceae and many nodes supporting members that have been recognized to comprise these groups have weak bootstrap support (Figs. 1, 2, 3). Thus, despite the fact that most species are separated by well supported branches with non-zero lengths (exceptions will be discussed below), higher level relationships among species remain unclear. We did, however, find support for some hypothesized relationships. For example, our data support close relationships of $A$. fasciculata, A. purpurea, and A. paupercula in all trees (Figs 1,2,3). We also found support for a sister relationship between A. setacea and A. plukenettii in the full data set (Fig. 3) that had previously been hypothesized based on both species having acute trichomes [41]. We found no support for a close relationship of A. laxa to these two taxa in the full data set but $A$. laxa and A. plukenettii were part of a poorly supported clade that also comprised the A. tenuifolia/A. gattingeri/A. maritima clade in the ITS tree. Although it had been classified with A. setacea and A. plukenettii in Subsection Setaceae, Agalinis laxa was known to differ in having capitate trichomes on the hypocotyls and lacking acute trichomes [41].

Overall, our results suggest that North American members of the genus comprise six major lineages, however we were not able to resolve branching order among many of these lineages. We propose that Section Heterophyllae consisting of A. calycina, A. heterophylla (and potentially A. densiflora but we did not sample this species) represents the basal group. Following the divergence of Section Heterophyllae, a rapid diversification resulted in five additional primary lineages. These lineages include one comprising what have been considered Section Erectae and Subsection Pedunculares, two unrelated monospecific lineages (one comprising A. auriculata and the other A. linifolia), a fourth lineage corresponding roughly to Section Tenuifolieae, and a fifth consisting of the remaining taxa that have been included in Section Purpureae. We further recognize Section Erectae (sans A. gattingeri) and what was Subsection Pedunculares as distinct sister lineages that are relatively derived within the genus.

One potential explanation for lack of bootstrap support for the more basal relationships in the genus is a rapid diversification of lineages (i.e., a hard polytomy) [e.g., [86]]. This explanation is also supported by presence of comparatively short branches towards the base of the phylogeny (Fig. 3). Alternatively our data may simply not be sufficient to determine the order of branching (i.e., a soft polytomy) [e.g., [86]]. Although there is the potential that sequencing additional nuclear loci may be able to resolve the branching order at interior nodes on the phylogeny, we believe that a soft polytomy seems unlikely given the amount of DNA sequence we sampled and the levels of variation we observed in those sequences. Because our objectives included estimating both deep and shallow relationships, we specifically chose an array of loci that were expected to be useful for estimating relationships across the ranges of divergence anticipated.

\section{Testing Species-level hypotheses}

Our results corroborate most of the species designations in the genus and clarify some previous taxonomic ambiguities. Based on likelihood ratio tests, $83 \%$ (24 of 29 ) sampled species in the genus have significant (non-zero) branch lengths and $78 \%$ of species with multiple samples have bootstrap support $>98 \%$. There are also multiple cases in which branch lengths between conspecific individuals are greater than zero (e.g. the two A. aphylla samples [Fig. 3]) indicating that there is substantial differentiation among conspecific populations. Although we do not believe that there is a single particular amount of differentiation that determines a cutoff for recognizing a species-level distinction, we do expect populations within species to lack strong hierarchical structure due to tokogenetic processes [87]. The hierarchical structure indicated by significant branch lengths and high bootstrap support within species (e.g., A. skinneriana, A. decemloba, A. oligophylla, A. fasciculata, and A. tenuifolia) indicates the need for closer examination of the biological basis of the observed patterns. Sampling additional loci and populations and using phylogeographic analytical 
methods would contribute to understanding whether these populations actually represent different species.

Exceptions to overall pattern of monophyly described above are the apparent polyphyly of $A$. harperi; the lack of differentiation between A. purpurea and A. paupercula; and the lack of differentiation among $A$. decemloba, A. tenella, and $A$. acuta (Figs. 1, 2, 3). All rare species that are of conservation concern except A. acuta and A. paupercula were supported as distinct.

The two sampled A. harperi individuals had identical ITS sequences (Fig. 2) but were polyphyletic based on cpDNA data (Fig. 1). Both individuals were part of a moderately supported clade (bootstrap support $=83 \%$ ) consisting of representatives of putative A. purpurea and A. paupercula, A. fasciculata and A. gattingeri individuals. However, A. harperi $13 \mathrm{FL}$ is most closely related to A. gattingeri and the other appears sister to the A. fasciculata/A. purpurea/A. paupercula clade (Fig. 1). Reamplification and sequencing of $r p o \mathrm{~B}, r p s 2$, and $\operatorname{trn} \mathrm{T}-\operatorname{trn} \mathrm{F}$ loci from the two A. harperi samples yielded sequences that were identical to those used in constructing the phylogenies, thus ruling out the possibility that samples were mishandled. Therefore, the difference between the cpDNA and nDNA may be best explained by hybridization or introgression from another species that is represented by chloroplast capture [88]. Although it is not possible to say with much certainty given the lack of statistical support for the relationship between the A gattingeri samples and A. harperi 13FL, A. gattingeri may be the species from which cpDNA has introgressed into the A. harperi collection from Florida. Sampling from more A. harperi and A. gattingeri individuals and populations is required to resolve this issue.

Agalinis purpurea and A. paupercula have been the subject of debate, with taxonomic hypotheses ranging from treating them as two species, as two varieties of A. purpurea, or synonymizing them under a single species. Pennell suggested relatively recent divergence related to the last ice age [22]. These putative taxa differ from one another in that A. paupercula is reported to have smaller corollas (10$20 \mathrm{~mm}$ ) and broader calyx lobes that are greater than half the length of the calyx tube [22]. Agalinis purpurea has corollas ranging from 18-38 mm long and narrow calyx lobes that are less than half the length of the tube. Although they share many features during floral ontogeny, they do differ in A. paupercula var. borealis having different anther orientation, filament insertion points closer to the ovary height, later stigma initiation, and less exsertion of the stigma at anthesis than A. purpurea [44]. The effect of these characteristics on mating system or reproductive isolation is unknown. It is also not known if these characteristics extend to other A. paupercula varieties. Our data do not support recognizing A. paupercula as a distinct taxon. However, we did not thoroughly sample from a large number of putative populations of A. paupercula and it remains possible that some populations that have been attributed to that species represent a distinct entity. Further it is possible that higher resolution markers would allow us to differentiate A. paupercula and A. purpurea as is discussed below for A. acuta.

One of the primary objectives of this study was to evaluate the evolutionary distinctiveness of the federally listed endangered species Agalinis acuta. Potential synonymy of A. acuta with A. tenella was raised by Neel and Cummings [47] due to lack of sequence divergence in two cpDNA loci between two individuals. Sampling nine representatives of A. acuta and five of A. tenella in this study allowed us to more thoroughly examine this issue. Previous taxonomic revisions [53] that synonymized A. tenella and A. decemloba with A. obtusifolia necessitated inclusion of accessions attributed to the latter two species. Rather than clarifying relationships among these taxa, our results show a more convoluted situation than was previously thought to exist. The ITS phylogeny shows A. tenella, A. acuta, A. decemloba and A. obtusifolia to be polyphyletic (Fig. 3); however, there is little support for this topology. The phylogenies based on cpDNA loci alone and all loci combined (Figs. 1 \&3, respectively) show A. tenella to be monophyletic and subtended by a branch with a length that is significantly different from zero based on the likelihood ratio test. There is, however, no bootstrap support for this clade and it is nested within a clade that includes $A$. acuta and $A$. decemloba. On both topologies, A. acuta and A. decemloba are polyphyletic (Figs. $1 \& 3$ ) and an AU test indicated that forcing the monophyly of A. acuta and A. tenella yielded a topology that was significantly worse than the best topology for all three datasets $(P<0.05)$. Although A. acuta, A. decemloba, and $A$. tenella form a highly supported monophyletic clade, one accession of A. decemloba (6VA) is distinguished from all other accessions of these three taxa based on branch lengths that are significantly different than zero and $98 \%$ bootstrap support (Fig. 3). This differentiation is the result of differences within the $\operatorname{trn} \mathrm{T}-\operatorname{trn} \mathrm{F}$ locus. These include numerous single nucleotide differences and a 16 bp deletion, the majority of which are also present in the A. obtusifolia samples.

Regardless, our results do not provide statistical support for separate species status for A. acuta, A. decemloba, and A. tenella under the criteria of either a phylogenetic species concept [89] or a genealogical species concept [11]. Agalinis obtusifolia comprises a monophyletic clade that is sister to the clade containing A. skinneriana, and A. tenella, A. acuta, and $A$. decemloba, thus strongly refuting the recent taxonomic revision synonymizing both $A$. decemloba and A. tenella with A. obtusifolia [e.g., [27,53]]. 
Lack of monophyly of even morphologically well defined species can result from incomplete lineage sorting of shared ancestral polymorphism or contemporary gene flow $[16,17,90]$. Given that it takes on the order of $\sim 8.7 \mathrm{~N}_{e}$ generations for an 0.95 probability of reciprocal monophyly to evolve at a single locus after speciation events $[17,20]$, it can be challenging to distinguish among closely related taxa using phylogenetic methods. It is also possible that the DNA sequences we examined do not have sufficient mutation rates to have accumulated nucleotide differences in the time since divergence. However, the loci sampled appear to have a sufficient amount of variation to distinguish $\sim 83 \%$ of the 29 sampled species in the genus, some of which are likely to have recently diverged from a common ancestor. Due to the important policy implications of combining A. acuta, A. tenella, and A. decemloba into a single taxon, additional research is being conducted on the morphological and genetic differences, using more variable loci, from samples collected from throughout the range of each species.

As mentioned above, we found that A. skinneriana formed a well supported clade that was sister to the clade containing A. tenella, A. decemloba, and A. acuta (Figs. 1 \&3). Prior to this work, taxonomic boundaries and phylogenetic affinities of A. skinneriana were not understood. Additionally, the Maryland populations that we sampled were problematic for experts to identify because these populations were beyond the known range for the species at the time they were discovered. The morphological characteristics of A. skinneriana most closely matched these populations, but there was some lingering question as to their identity. Our results confirm that these populations are sister to the A. skinneriana sample from Missouri and they represent an extension of this otherwise Midwestern prairie taxon to the grasslands of the Atlantic coastal plain. However, the branch separating the Maryland populations from the Missouri population is significantly different from zero indicating that further investigation of the phylogeography of this putative species may be warranted to determine if the Maryland populations are actually an unrecognized species. Clarifying these relationships is important because this species is considered rare in the state of Maryland and correct identification is essential for both protecting a rare entity and not imposing restrictions for something that does not warrant them.

\section{Conclusion}

In conclusion, the sampled Agalinis species form a well supported, monophyletic group relative to the other genera sampled from within the family Orobanchaceae. Despite the well known taxonomic difficulty in this genus, 24 of the 29 the species we sampled that had been recognized based on anatomy and morphology were well supported. We confirmed the monophyly of 19 rare spe- cies, thus supporting their eligibility for receiving conservation attention. The species that do not form well supported clades based on DNA sequence data include the federally listed species A. acuta and the state-rare species A. paupercula. Although we were able to resolve some relationships among these species, most notably that the synonymization of the latter two with A. obtusifolia is unwarranted, a number of ambiguities remain. Due to the important policy implications raised by this finding, we are examining relationships among A. acuta, A. decemloba, and $A$. tenella further by sampling more individuals and populations using higher resolution molecular markers and morphological data. It is clear that most hypotheses regarding section- and subsection-level relationships based on morphology are not supported and taxonomic revisions are warranted.

\section{Authors' contributions}

MCN conceived of the study and obtained funding. JBP carried out laboratory work and analyses. Both authors participated in sequence alignment, interpretation of results, and writing of the manuscript.

\section{Additional material}

\section{Additional file 1}

General population locations and Genbank accession numbers for loci sampled from North American Agalinis species examined in this study. Section and subsection classifications follow J.M. Canne-Hilliker. Genbank accession numbers for those sequences with "N \& C (2004)" can be found in Neel and Cummings (2004).

Click here for file

[http://www.biomedcentral.com/content/supplementary/14712148-8-264-S1.pdf]

\section{Acknowledgements}

The authors thank JM Canne-Hilliker, G Dieringer, J Koontz, D Lewis, JL Neff, and P Polloni for collecting specimens; C Frye, B Gulotta, B Horwith, M Jordan, N Murray, M Pelikan, P Polloni, C Raithel, S Ruhren, P Somers, B Sorrie, W Tyndall, and B Zaremba for assistance in locating populations for collection and for facilitating permits; JM Canne-Hilliker and J Hays for helpful discussions regarding the taxonomy of Agalinis; AM Lewis and M Linares for assistance with laboratory work; and M Cummings, J Hall, A Kawahara, $C$ Mitter, and R Timme for helpful discussions regarding phylogenetic analyses. US Fish and Wildlife Service and the Maryland Agricultural Experiment Station partially funded this work.

\section{References}

I. Soltis EDS, P S: Contributions of plant molecular systematics to studies of molecular evolution. Plant Mol Biol 2000, 42:45-75.

2. Beardsley PM, Schoenig SE, Whittall JB, Olmstead RG: Patterns of evolution in western North American Mimulus (Phrymaceae). Am J Bot 2004, 91:474-489.

3. Palmer JD, Soltis DE, Chase MW: The plant tree of life: An overview and some points of view. Am J Bot 2004, 9 I: | 1437-I 445.

4. Barraclough TG, Nee S: Phylogenetics and speciation. Trends Ecol Evol 2001, 16:391-399. 
5. Andreasen K: Implications of molecular systematic analyses on the conservation of rare and threatened taxa: Contrasting examples from Malvaceae. Conserv Genet 2005, 6:399-412.

6. Soltis PS, Gitzendanner MA: Molecular systematics and the conservation of rare species. Conserv Biol 1999, 13:47I-483.

7. Crandall KA, Bininda-Emonds ORP, Mace GM, Wayne RK: Considering evolutionary processes in conservation biology. Trends Ecol Evol 2000, 1 5:290-295.

8. Fallon SM: Genetic data and the listing of species under the U.S. Endangered Species Act. Conserv Biol 2007, 21: I I 86-I I 95.

9. $\mathrm{Wu} \mathrm{Cl}$ : The genic view of the process of speciation. J Evolution Biol 200I, 14:85I-865.

10. Sokal RR, Crovello TJ: The biological species concept: a critical evaluation. Am Nat 1970, 104: I27-153.

II. Baum DA, Shaw KL: Genealogical perspectives on the species problem. In Monographs in Systematic Botany: Experimental and molecular approaches to plant biosystematics Missouri Botanical Garden, St. Louis; 1995:289-303.

12. Donoghue MJ: A critique of the biological species concept and recommendations for a phylogenetic alternative. Bryologist 1985, 88:172-181.

13. Mallet J: A species definition for the modern synthesis. Trends Ecol Evol 1995, 10:294-299.

14. Sites JW Jr, Marshall JC: Empirical criteria for delimiting species. Annu Rev Ecol Evol Syst 2004, 35: 199-229.

15. Syring J, Farrell K, Businsky R, Cronn R, Liston A: Widespread genealogical nonmonophyly in species of Pinus subgenus Strobus. Syst Biol 2007, 56:163-181.

16. Funk DJ, Omland KE: Species-level paraphyly and polyphyly: frequency, causes and consequences with insights from animal mitochondrial DNA. Annu Rev Ecol Evol Syst 2003, 34:397-423.

17. Hudson RR, Coyne JA: Mathematical consequences of the genealogical species concept. Evolution 2002, 56: I557-I565.

18. Takahata N: Gene genealogy in three related populations: consistency probability between gene and population trees. Genetics 1989, 122:957-966.

19. Tajima F: Evolutionary relationships of DNA sequences in finite populations. Genetics 1983, 105:437-460.

20. Rosenberg NA: The shapes of neutral gene genealogies in two species: probabilities of monophyly, paraphyly, and polyphyly in a coalescent model. Evolution 2003, 57: I465- I 477.

21. Knowles LL, Carstens BC: Delimiting species without monophyletic gene trees. Syst Biol 2007, 56:887-896.

22. Pennell FW: The Scrophulariaceae of eastern temperate North America (4I Gerardia). Academy of Natural Sciences of Philadelphia Monographs 1935, I:419-476.

23. Pennell FW: Agalinis and allies in North America II. P Acad Nat Sci Phila 1929, 81: I I I-249.

24. Pennell FW: Agalinis and allies in North America I. P Acad Nat Sci Phila 1928, 80:339-449.

25. Canne-Hilliker JM: Agalinis (Scrophulariaceae) in Peru and Bolivia. Brittonia 1988, 40:433-440.

26. Missouri Botanical Garden: The VAST (VAScular Tropicos) Database. Missouri Botancial Garden; 2007

27. USDA NRCS: The PLANTS Database. National Plant Data Center. 2008 [http://plants.usda.gov].

28. dePamphilis CW, Young ND, Wolfe AD: Evolution of plastid gene rps2 in a lineage of hemiparasitic and holoparasitic plants: Many losses of photosynthesis and complex patterns of rate variation. P Natl Acad Sci USA 1997, 94:7367-7372.

29. Olmstead RG, Reeves PA: Evidence for the polyphyly of the Scrophulariaceae based on chloroplast rbc $L$ and ndhF sequences. Ann Mo Bot Gard 1995, 82: 176-193.

30. Olmstead RG, DePamphilis CW, Wolfe AD, Young ND, Elisons W], Reeves PA: Disintegration of the Scrophulariaceae. Am J Bot 200I, 88:348-36I.

31. Pennell FW: Studies in the Agalinanae, a subtribe of the Rhinanthaceae. I. Nomenclature of the Neartic genera. B Torrey Bot Club 1913, 40:119-130.

32. Pennell FW: Studies in the Agalinanae, a subtribe of the Rhinanthaceae. II. Species of the Atlantic Coastal Plain. B Torrey Bot Club 1913, 40:40I-439.

33. Canne JM: Seed surface features in Aureolaria, Brachystigma, Tomanthera, and certain South American Agalinis (Scrophulariaceae). Syst Bot 1980, 5:24I-252.
34. Canne JM: A light and scanning electron microscope study of seed morphology in Agalinis (Scrophulariaceae) and its taxonomic significance. Syst Bot 1979, 4:28I-296.

35. Dieringer $\mathrm{G}$ : Variation in individual flowering time and reproductive success of Agalinis strictifolia (Scrophulariaceae). Am J Bot |99|, 78:497-503.

36. Neel MC: Conservation implications of the reproductive ecology of Agalinis acuta (Scrophulariaceae). Am J Bot 2002, 89:972-980

37. Dieringer G: Reproductive biology of Agalinis skinneriana (Scrophulariaceae), a threatened species. J Torrey Bot Soc 1999, 126:289-295.

38. Snider JA: A variation study of Agalinis decemloba (Greene) Pennell and Agalinis obtusifolia Raf. in the Carolinas. Unpublished Master of Arts thesis, University of North Carolina at Chapel Hill, Chapel Hill, North Carolina; 1969.

39. Mulvaney CR, Molano-Flores B, Whitman DW: The reproductive biology of Agalinis auriculata (Michx.) Raf. (Orobanchaceae), a threatened North American prairie inhabitant. Int J Plant Sci 2004, 165:605-6I4.

40. Stewart HM, Stewart SC, Canne-Hilliker JM: Mixed mating system in Agalinis neoscotica (Scrophulariaceae) with bud pollination and delayed pollen germination. Int J Plant Sci 1996, I57:50I-508.

4I. Canne JM: The taxonomic significance of seedling morphology in Agalinis (Scrophulariaceae). Can J Bot 1983, 62:454-456.

42. Canne-Hilliker JM, Kampny CM: Taxonomic significance of leaf and stem anatomy of Agalinis (Scrophulariaceae) from the U.S.A. and Canada. Can J Bot 1991, 69:1935-1950.

43. Canne JM: Chromosome numbers and the taxonomy of North American Agalinis (Scrophulariaceae). Can J Bot 1984, 62:454-456.

44. Stewart HM, Canne-Hilliker JM: Floral development of Agalinis neoscotica, Agalinis paupercula var. borealis, and Agalinis purpurea (Scrophulariaceae): Implications for taxonomy and mating system. Int J Plant Sci 1998, 159:418-439.

45. Canne JM: Chromosome counts in Agalinis and related taxa (Scrophulariaceae). 1981, 59: I III-III6.

46. Canne-Hilliker JM: Patterns of floral development in Agalinis and allies (Scrophulariaceae). II. Floral development of Agalinis densiflora. Am J Bot 1987, 74:1419-1430.

47. Neel MC, Cummings MP: Section-level relationships of North American Agalinis (Orobanchaceae) based on DNA sequence analysis of three chloroplast gene regions. $B M C$ Evol Biol 2004, 4:15.

48. Wiens JJ, Servedio MR: Species delimitation in systematics: inferring diagnostic differences between species. $P$ Roy Lond $B$ Bio 2000, 267:631-636.

49. Baum DA: Individuality and the existence of species through time. Syst Biol 1998, 47:64|-653.

50. NatureServe Explorer: An online encyclopedia of life [web application]. Version 6.3. NatureServe, Arlington, Virginia [http://www.natureserve.org/explorer]

51. Redding DW, Mooers AO: Incorporating evolutionary measures into conservation prioritization. Conserv Biol 2006, 20:1670-1678.

52. Moritz C: Uses of molecular phylogenies for conservation. Phil Trans R Soc Lond B 1995, 349: I 13-118.

53. Kartesz JT: A synonymized checklist and atlas with biological attributes for the vascular flora of the United States, Canada, and Greenland. In Synthesis of the North American Flora, Version 10 First edition. Edited by: Kartesz JT, Meacham CA. Chapel Hill, NC: North Carolina Botanical Garden; 1999.

54. U. S. Fish and Wildlife Service: Determination of Agalinis acuta to be an endangered species. Federal Register 1988, 53:3470I-34705.

55. U.S.C: Endangered Species Act \$I53I-\$I544. 1973.

56. Shaw J, Lickey EB, Beck JT, Farmer SB, Liu WS, Miller J, Siripun KC Winder CT, Schilling EE, Small RL: The tortoise and the hare II: Relative utility of 21 noncoding chloroplast DNA sequences for phylogenetic analysis. Am J Bot 2005, 92: I42-I66.

57. Small RL, Ryburn JA, Cronn RC, Seelanan T, Wendel JF: The tortoise and the hare: Choosing between noncoding plastome and nuclear ADH sequences for phylogeny reconstruction in a recently diverged plant group. Am J Bot 1998, 85: I30I-1315.

58. Baldwin BG: Adaptive radiation of shrubby tarweeds (Deinandra) in the California Islands parallels diversification of the 
Hawaiian silversword alliance (Compositae-Madiinae). Am J Bot 2007, 94:237-248.

59. Taberlet P, Gielly L, Pautou G, Bouvet J: Universal primers for amplification of 3 noncoding regions of chloroplast DNA. Plant Mol Biol 1991, 17: I 105-II09.

60. Alvarez I, Wendel JF: Ribosomal ITS sequences and plant phylogenetic inference. Mol Phylogenet Evol 2003, 29:4I7-434.

61. White TJ, Bruns T, Lee S, Taylor J: Amplification and direct sequencing of fungal ribosomal RNA genes for phylogenetics. In PCR Protocols: A Guide to Methods and Applications Edited by: M. I, Gelfand D, Sninsky J, White T. San Diego: Academic Press; 1990:315-332.

62. Edgar RC: MUSCLE: multiple sequence alignment with high accuracy and high throughput. Nucleic Acids Research 2004 32: $1792-1797$

63. Hall TA: BioEdit: a user-friendly biological sequence alignment editor and analysis program for Windows 95/98/NT. Nucleic Acids Symposium Series 41:95-98: 19991999.

64. Maddison W, Maddison D: MacClade 4.06 software. Sunderland: Sinauer Associates; 200I.

65. Swofford DL: PAUP*. Phylogenetic Analysis Using Parsimony (*and Other Methods). Version 4.0. Sunderland: Sinauer Associates; 2003.

66. Posada D, Crandall KA: MODELTEST: testing the model of DNA substitution. Bioinformatics 1998, 14:817-818.

67. Zwickl DJ: Genetic algorithm approaches for the phylogenetic analysis of large biological sequence datasets under the maximum likelihood criterion. In Ph.D. dissertation The University of Texas at Austin; 2006.

68. Yang ZB: Estimating the pattern of nucleotide substitution. J Mol Evol I 994, 39: I05- I II.

69. Gu X, Fu YX, Li WH: Maximum-likelihood-estimation of the heterogeneity of substitution rate among nucleotide sites. Mol Biol Evol 1995, 1 2:546-557.

70. Lewis PO: A genetic algorithm for maximum-likelihood phylogeny inference using nucleotide sequence data. Mol Biol Evol 1998, I5:277-283.

7I. Bazinet AL, Cummings MP: The Lattice Project: a grid research and production environment combining multiple grid computing models. In Distributed \& Grid Computing - Science Made Transparent for Everyone Principles, Applications and Supporting Communities Edited by: Weber MHW. Marburg: Tectum Publishing House in press.

72. Bazinet AL, Myers DS, Fuetsch J, Cummings MP: Grid Services Base Library: A high-level, procedural application programming interface for writing Globus-based Grid services. Future Gener Comp Sy 2007, 23:517-522.

73. Shimodaira $\mathrm{H}$ : An approximately unbiased test of phylogenetic tree selection. Syst Biol 2002, $51: 492-508$.

74. Shimodaira $\mathrm{H}$, Hasegawa M: CONSEL: for assessing the confidence of phylogenetic tree selection. Bioinformatics 200I, 17:1246-1247.

75. Yang FS, Wang XQ: Extensive length variation in the cpDNA trn T-trnF region of hemiparasitic Pedicularis and its phylogenetic implications. Plant Syst Evol 2007, 264:25I-264.

76. de Oliveira L, de Sousa F, Wendt T, Brown GK, Tuthill DE, Evans TM Monophyly and phylogenetic relationships in Lymania (Bromeliaceae : Bromelioideae) based on morphology and chloroplast DNA sequences. Syst Bot 2007, 32:264-270.

77. Yang FS, Wang XQ, Hong DY: Unexpected high divergence in nrDNA ITS and extensive parallelism in floral morphology of Pedicularis (Orobanchaceae). Plant Syst Evol 2003, 240:91-105.

78. Schneeweiss GM, Colwell A, Park JM, Jang CG, Stuessy TF: Phylogeny of holoparasitic Orobanche (Orobanchaceae) inferred from nuclear ITS sequences. Mol Phylogenet Evol 2004, 30:465-478.

79. Levin RA, Wagner WL, Hoch PC, Hahn WJ, Rodriguez A, Baum DA, Katinas L, Zimmer EA, Sytsma KJ: Paraphyly in tribe Onagreae: Insights into phylogenetic relationships of Onagraceae based on nuclear and chloroplast sequence data. Syst Bot 2004, 29:147-164

80. Soltis DE, Kuzoff RK: Discordance between nuclear and chloroplast phylogenies in the Heuchera group (Saxifragaceae). Evolution 1995, 49:727-742.
8I. Baumel A, Ainouche ML, Bayer RJ, Ainouche AK, Misset MT: Molecular phylogeny of hybridizing species from the genus Spartina Schreb. (Poaceae). Mol Phylogenet Evol 2002, 22:303-3I4.

82. Holder MT, Anderson JA, Holloway AK: Difficulties in detecting hybridization. Syst Biol 200I, 50:978-982.

83. Kimball RT, Crawford DJ, Smith EB: Evolutionary processes in the genus Coreocarpus : Insights from molecular phylogenetics. Evolution 2003, 57:52-61.

84. Kaplan NL, Darden T, Hudson RR: The coalescent process in models with selection. Genetics 1988, I 20:819-829.

85. Bennett JR, Mathews S: Phylogeny of the parasitic plant family Orobanchaceae inferred from phytochrome A. Am J Bot 2006 , 93:|039-105I.

86. Page RDM, Holmes EC: Molecular Evolution: A Phylogenetic Approach. Oxford: Blackwell Sciences; 1998.

87. Posada $D$, Crandall KA: Intraspecific gene genealogies: trees grafting into networks. Trends in Ecology \& Evolution 2001, 16:37-45.

88. Tsitrone A, Kirkpatrick M, Levin DA: A model for chloroplast capture. Evolution 2003, 57:1776-1782.

89. de Queiroz K, Donoghue MJ: Phylogenetic systematics and the species problem. Cladistics 1988, 4:317-338.

90. Broughton RE, Harrison RG: Nuclear gene genealogies reveal historical, demographic and selective factors associated with speciation in field crickets. Genetics 2003, 163:|389-|40|

Publish with BioMed Central and every scientist can read your work free of charge

"BioMed Central will be the most significant development for disseminating the results of biomedical research in our lifetime. "

Sir Paul Nurse, Cancer Research UK

Your research papers will be:

- available free of charge to the entire biomedical community

- peer reviewed and published immediately upon acceptance

- cited in PubMed and archived on PubMed Central

- yours - you keep the copyright
BioMedcentral 